\title{
The Impact of the Implementation of Saudi Arabia's Vision 2030 on Teaching English as a Foreign Language at Public Universities
}

\author{
Abdurrahman M. Alfahadi \\ Dept. of English Languages \& Translation, Faculty of Education \& Arts, \\ The University of Tabuk, Tabuk, Kingdom of Saudi Arabia
}

\begin{abstract}
The study aimed at examining the impact of the implementation of the Saudi Vision 2030 (SAV) on teaching English as a foreign language at public universities in the Kingdom of Saudi Arabia. SAV relates to the educational development in public sectors in general and English as a foreign language teaching at higher education sectors in particular. The study used the descriptive approach design deploying a questionnaire survey that comprised 19 items divided into four sections. The sample of the study consisted of 250 male and 250 female English as a foreign language teachers at different Saudi public universities in varied region in the Kingdom of Saudi Arabia. The findings of the research showed that the statistical analysis of the participants' responses showed that there is a high positive impact of VAS 2030 on the educational and professional development in Saudi Arabia in general and teaching English as a foreign language in particular. $90 \%$ of the participants indicated that there is statistically significant interrelation between the implementation of VAS 2030 and teaching EFL at higher education stage. Also, the findings of the study revealed that $90 \%$ of the participants demonstrated that the implementation of VAS 2030 will impact the development of the global image of teaching ELF in Saudi Arabia by becoming an attractive region for the spread of EFL in different sectors in the Kingdom of Saudi Arabia. In addition, the findings proposed that teaching EFL in the era of SAV 2030 will face many challenges and difficulties in terms of using high-tech teaching methods. This study recommends that further research be conducted in this field to support the findings of contemporary investigations.
\end{abstract}

Keywords: SAV 2030, EFL, Saudi Arabia, Higher Education, Public Universities.

DOI: $10.7176 / \mathrm{JLLL} / 56-06$

Publication date:May $31^{\text {st }} 2019$

\section{Introduction}

The cultural and social diversity of the world nations has become a sign of growth and development. This requires the availability of effective means of communication between nations to culturally and globally transform experiences and welfare amongst nations through an international language. Thus, English is the only language that could provide grounded base for international communication since it is the most used language amongst nations throughout the world (Melitz, 2008).

Therefore, there are varied elements that may result in the growth of nations worldwide which basically depends on the creativity of successful interaction amongst them. The Kingdom of Saudi Arabia has figured out such development leading to the foundation of Saudi Vision 2030 (VAS 2030, hereafter) by His Royal Highness (HRH) Prince Mohammed bin Salman bin Abdul Aziz, the deputy Crown Prince of the Kingdom of Saudi Arabia. VAS 2030, thus, takes into consideration the establishment a genuine academic system that depends on a mutual collaboration between both the private and public sectors in the Kingdom of Saudi Arabia in order to avoid the challenges that encounter decision makers in the international ties and global economical and political treaties with the Kingdom of Saudi Arabia (Al Zahrani, 2017).

Furthermore, VAS 2030 looks for providing a global understanding and collaboration between the Kingdom of Saudi Arabia and other nations worldwide in different areas including education, economic, politics or international trade etc as well as advancing the realm of the academic system by providing the necessary international training for lower and higher education cadres in the Kingdom of Saudi Arabia to meet the demands of expanding the process of teaching EFL in relevance with VAS 2030. In order to achieve the objectives of teaching EFL in line with the Saudi vision 2030, a number of precautious steps that include professional constant academic and educational training as well as a grounded educational setting in the field of teaching English as a foreign language in particular, apart from of the reality that English as a foreign language teachers are highly experienced and competent or not so that an appropriate learning outcomes will be achieved in relevance to VAS 2030 (Al-Sulami, 2016). This is because of the reality that contemporary investigations have shown that the general evaluation of most EFL teachers in KSA does not disclose the best possible levels that is demonstrated in fresh graduates' performance at higher education stage and university level which is inadequate (Al-Essa, 2009).

That is, the global dependence on oil consumption made the Kingdom of Saudi Arabia to commence a transformation into the kingdom's oil-dependent economy. The government of Saudi Arabia has taken varied actions to make some economical reformations in the kingdom in relevance with such efforts, His Royal 
Highness Prince Mohammed bin Salman announced Vision 2030. This resulted in the largest economic reforms and transformation since the establishment of the Kingdom of Saudi Arabia in 1932 (Yusuf, 2016). This means that there will be reformation for Saudi educational curriculum in line with VAS 2030 terms (Al-Maimooni, 2016). Because of the modernity of this research in line with the foundation of the 2030 vision, there is still a scarcity of research in that field. Though, there might have been some suggestions demonstrated by some national and international figures in academic and educational seminars held in the Kingdom of Saudi Arabia at Jeddah University in 2016. The recommendations of the seminars concluded that teaching EFL in relevance with VAS 2030 is very prospective and eventual. This is viewed in the transformation of the educational difficulties into speculative opportunities in order to accomplish the national transformation such as the foundation of EFL teaching centers and institutes, granting national and international diplomas targeting the availability of good quality teachers and learners, implementing the Saudi national standards for teaching as a profession securing social and educational stability so that a quality leap in EFL skills can be ensured (Al Sulami, 2016).

In addition, the demanding economic transformation which the kingdom experiences necessitates personal, professionals and academia's to be highly qualified and skillful in order to cope with the needs of the era and accept global challenging trends compared with the past time. This reveals that the time for preparing graduates for the market demands has come. VAS 2030 is viewed significant in EFL teaching and learning since it provides academia with the opportunities to invest in the educational sector and that advances national and international education training as well as teaching English as a foreign language in particular (Mahboob \& Elyas, 2014). To conclude, English is still treated in Saudi Arabia as foreign language and has not reached the level of becoming a second or official language. That is, EFL graduates experience a challenging reality with English language despite of the spending billions of Riyals on advancing the wheel of teaching English and updating the teaching materials since the time of the late King Abdullah, yet the dilemma still continues (Mosa, 2015).

Thus, the ministry of higher education resembled by the academic institutions in the kingdom of Saudi Arabia should double its efforts to advance the teaching of English as a foreign language so that the objectives of VAS 2030 can be met. In relevance, varied issues of English as a foreign language teaching must be discussed such as graduates' academic dishonesty that must be considered from social and educational point of views. VAS 2030, however, pulled the trigger towards achieving educational standards at the national and international levels. This proposes discussing two main points to advance the methods of teaching EFL according to Vision 2030. This includes the collaboration of social networking proposals and academic professional development to achieve the objectives of vision 2030 (Burden, 2012).

\section{Literature Review}

English has become the most widely used as an international language that connects the world as one global village. It has developed to be the mean of communication for people of different ethnic and cultural background throughout the world (Ur Rahman \& Alhaisoni, 2013). English language is the medium of instruction at both private and public sectors for some disciplines at public and private educational institutions in the Kingdom of Saudi Arabia right from nursery to higher education level (Yusuf, 2017). Thus, all public Saudi universities and higher education institutions necessitate EFL students to undergo a language proficiency test to obtain an opportunity and get enrolled in the desired discipline. As a result, the Ministry of Higher in Saudi Arabia has provided the necessary attention to advance the wheel of learning and teaching English as a foreign language due to its importance in different fields of education (Yusuf \& Atassi, 2016).

English language has become one of the most essential components in the stability of the global economic ties between nations and strategic partners. In addition, English language is a key success in achieving fruitful cultural and political understanding amongst countries of the world. Despite of the necessary attention provided by the Ministry of Higher education in Saudi Arabia, there are still different challenges and difficulties that encounter fresh EFL graduates at higher education stage in the Saudi Public Universities that might be associated with many socio-cultural, educational or economical factors; the most significant is related to the need for motivating EFL students to become skilled in English language (Al Mukhallafi, 2014). Research on EFL teaching and learning issues has developed rapidly over the past two decades. Investigation of English as a foreign language teaching and learning at higher education level is one of the more specific areas that have gained prominence (Al-Nasser, 2015). This significance of such studies cannot be denied as linguistic knowledge can be a helpful insight to provide solutions to language based-problems.

Al Zahrani (2017) conducted a study to investigate the markets and language policy in Saudi Arabia in terms of how English language can contribute to the success of the Saudi vision 2030. The study targeted the educational system and language policy in the Kingdom of Saudi Arabia and its relatedness to the gaps of the global markets. This study found out that there are different concerns that should be taken into consideration by scholars and researchers such as identifying how individuals can be helped to achieve economic goals. Also, the findings of the study showed that language education should be considered as part of the Saudi Vision 2030. To 
conclude, this research recommended that contemporary practices of English language teaching and learning may be inappropriate for meeting the Vision 2030 objectives so curriculum designers should consider such point and further research be conducted in this field.

In another study, Yusuf (2017) examined the changes required in Saudi universities curriculum to meet the demands of 2030 Vision. The sample of the study included the existing curriculum and associated problems with Saudi universities. The findings of this qualitative study showed that there are certain barriers that may influence the implementation of the vision 2030 adversely in Saudi Arabia. Further, this research recommended that future research studies to be conducted that may look into more areas of educational sector.

Similarly, Mitchell and Al Furaih (2017) analyzed English language teaching in the Kingdom of Saudi Arabia: Past, Present and Beyond. The goal of this study is to investigate English language teaching curriculum for Elementary, Intermediate and Secondary Schools in the Kingdom of Saudi Arabia Grades 4-12 between the year $2014-2020$. The findings of this research showed that there is more than needs to be done to support the continual improvement in the learning and teaching of English as the Kingdom continues to move into the developed world with less reliance on oil and a focus on becoming a knowledge based society. In addition, the Kingdom of Saudi Arabia's National Transformation Program and Vision 2030 support and provide the blueprint for this goal to be achieved. Consequently, this investigation recommends and encourages further research.

In conclusion, the researcher agrees with the above discussed studies that 2030 vision in Saudi Arabia will have a great effect on the development of English as a foreign language teaching in a Saudi EFL context. In addition, any kind of investigation should always start within the era of 2030 vision as it contains the basic philosophy of English as a foreign language teaching in the Kingdom of Saudi Arabia in the near future (Mitchell and Al Furaih, 2017). The researcher also observes that many research studies (Al-Essa, 2009; Ur Rahman \& Alhaisoni, 2013; Al-Nasser, 2015; Al Sulami, 2016 and Al Zahrani, 2017) have investigated this aspect and showed their concerns about the significance of 2030 towards the development and growth of EFL teaching and learning in Saudi Arabia. Although, there are many studies that investigated EFL and 2030 Vision relatedness, but not much research has so far examined the impact of the implementation of Saudi Arabia's Vision 2030 on teaching English as a foreign language at public universities, particularly in a Saudi context.

\section{Statement of the Problem}

English is taught in the Kingdom of Saudi Arabia as EFL whereby graduates are expected to master all the four basic language skills i.e. reading, listening, speaking, and writing. But, most of the EFL Saudi fresh graduates face difficulty when teaching EFL in classroom setting (Mahboob \& Elyas, 2014). One of the major problems is that fresh English as a foreign language graduates at higher education stage face challenges and difficulties in using effective teaching techniques. This eventually does not impact positively the performance of higher education students when learning EFL (Al Zahrani, 2017). Consequently, the Ministry of Higher Education used varied professional development techniques including service training programs so that EFL teachers could overcome the problems and challenges of teaching English within classroom setting (Ur Rahman \& Alhaisoni, 2013). Despite the efforts provided by decision makers and course materials designers to overcome EFL teaching problems, teachers and learners still encounter many challenges that obstruct their language learning performances.

In relation, the researcher believes that EFL teachers and learners lack of interaction and creativity in the process of EFL teaching is the basic problem in this respect. In this regard, the researcher thinks there is a need for developing the education and communicative competence of EFL teachers and learners. In addition, there is a necessity for understanding the fundamental nature of EFL teaching to be constant with SAV 2030 so that language teachers and learners could obtain the most appropriate and finest level of education at higher education in the Kingdom of Saudi in general, and teaching EFL in particular. As a result, the researcher felt that there is a need to conduct this type of research to investigate the impact of the implementation of SAV 2030 on teaching English as a foreign language at higher education stage in Saudi Arabia. Also, the researcher felt the necessity and need to investigate this issue as any future professional development would affect the readiness of EFL teachers and their adeptness.

\section{Research Objectives}

The main goal of this research study is to acquire data on the impact of the implementation of Saudi Arabia's Vision 2030 ( VAS 2030, hereafter) on teaching English as a foreign language at higher education stage produced by 500 male and female Saudi EFL teachers teaching at varied Saudi Public Universities. In relation to this issue, this study aims to achieve the following objectives.

i. To investigate the impact of the implementation of VAS 2030 on teaching EFL at higher education stage in Saudi Arabia.

ii. To examine EFL teachers at higher education stage perceptions teaching English as a foreign language 
in relevance to the implementation of VAS 2030 as well as their readiness in raising fresh graduates' performance at higher education stage in Saudi public universities.

iii. To analyse the effect of the implementation of VAS 2030 on the professional development of EFL teachers at higher education stage in Saudi public universities.

\section{Research Questions}

In order to achieve the objectives of this research study, the present study aims at addressing the following research questions:

i. To what extent the does implantation of VAS 2030 affect EFL teaching at higher education stage in Saudi Arabia?

ii. What is the perceptions of EFL teachers at higher education stage towards teaching English as a foreign language in relevance to the implementation of VAS 2030 as well as their readiness in raising fresh graduates' performance at higher education stage in Saudi public universities?

iii. How does the implementation of VAS 2030 affect the professional development of EFL teachers at higher education stage in Saudi public universities?

\section{The Significance of the Study}

The present study is conducted to assist English as foreign language (EFL) learners at higher education level to understand the significance of the impact of the implementation of VAS 2030 on teaching English as a foreign language at higher education stage. This study would help EFL learners by providing them with new knowledge and skills to be ready and aware of the challenges and difficulties that they may face when teaching EFL the time of implementing VAS 2030. Even though an EFL learner might possess practical knowledge of the grammar of the target language, they might not possess the appropriate professional development to cope with the demands of VAS 2030. Therefore, this study which examines the impact of the implementation of VAS 2030 on teaching English as a foreign language at higher education stage hopes to provide learners with a deeper understanding and insight to enhance their awareness of the significance of the implementation of VAS 2030 and its contribution to the growth of teaching EFL in the Kingdom of Saudi Arabia. This research study is also useful for EFL teachers. It would provide them further insights that can be used for further significance and enhance their teaching methods. It is hoped that the findings of this study will enable the teachers to be more constructive to their EFL learners language learning process. It would also help them by providing suggestions on the kind of teaching materials and textbooks that are to be utilized within the era of SAV 2030. It will also provide suggestions to curriculum planners and material writers and designers to integrate components that emphasize professional development, teachers' readiness, awareness of the latest teaching methods practices. In this regard, the findings and results of this research study can contribute significantly to research on teaching English within the era of SAV in 2030 in a Saudi EFL context.

\section{Research Methodology}

The researchers used a questionnaire survey to elicit data from the participants in order to answer the research questions. The research instrument used in this research study is both adopted and adapted. Means and standard deviations were calculated to identify the impact of the implementation of the Saudi 2030 Vision on teaching EFL at higher education stage at the Saudi public universities. The research sample consisted of 500 (250 male and 250 female EFL teachers). The sample was randomly selected without any bias towards gender, age or area. EFL teachers at Saudi universities generally come from different cities and towns in the Kingdom of Saudi Arabia. The population represents almost all the existing socio-economic classes such as low, middle, and high classes in the country since social-class differences that are reflected and reproduced in schools have profound effects on students' writing achievements. They are similar in age, ranging from 35-50 years, but different in gender. They are also homogenous with regard to nationality, native language (Arabic), language proficiency and educational background. The researchers used a checklist of English as a foreign language teaching criteria at Saudi public universities in line with the 2030 vision by reviewing the literature and past research in the field of English language teaching. In order to achieve the validity and reliability of the research instruments, the researcher prepared and piloted the questionnaire survey using EFL teachers / participants that were not involved in the main study sample in order to confirm readiness of the questionnaire to be provided to the respondents. The researcher used Microsoft Excel and IBM SPSS for analyzing and processing the elicited data.

\section{Results and Discussion}

In order to achieve the objectives of this study, the researcher validated the research questionnaire by a group of juries specialized in the field of EFL teaching and educational research and instructions. The jury demonstrated that the research instrument items (questionnaires) is well-constructed, organized, appropriate, linguistically clear in terms of content and context to the degree that meets the qualifications of Saudi EFL teachers at public 
universities. Also, the research instrument was validated using 25 male and female EFL teachers selected randomly from Saudi public universities. The sample participating in the pilot study were not involved in the main study. The researcher sent the questionnaire was electronically to the sample of the study that comprised 250 female teachers and 250 male teachers making a total of 500 participants all together. The results and findings of the study were analyzed using SPSS statistical analyses for participants' performance. Further, the researcher calculated the Cronbach 's Alpha coefficient to check the internal consistency of the research instruments. The internal consistency of the research instrument was viewed to be 0.81 which is an adequate value for achieving the objectives of this study (Dileo, 2014). This is in addition to the calculation of Pearson's correlation to ensure the validity of the research questionnaires. The correlation coefficients showed positivity and were statistically significant and acceptable at 0.01 level. All correlation coefficients between the impact of 2030 vision and the total score were positive and ranged between 0.63 and 0.87 . Therefore, the achieved correlation coefficients sought appropriate in the context of this research.

\subsection{The Results of the Study}

Since the researcher used a Likert five-point scale in its foremost analytical descriptive items, each participant's response was coded as follows: strongly agree $=5$, agree $=4$, undecided (I do not know) $=5$, disagree $=2$, and Strongly disagree $=1$. Further, "strongly agree" and "agree" preferences were treated as positive items. Also, "disagree" and "strongly disagree" were treated as negative items. Consequently, the results achieved by the researcher in this concern associated with research question one, " To what extent the does implantation of VAS 2030 affect EFL teaching at higher education stage in Saudi Arabia?" . In relation, Figure 1.1 in the following section depicts the positive effect of the implementation of VAS 2030 on teaching EFL at higher education stage in Saudi Arabia. The responses of the participants show that $90 \%$ of the male EEFL teachers indicated positive and $6 \%$ of them reported negative and $4 \%$ showed no responses. Whilst, $83 \%$ of the female EFL teachers revealed positive and $17 \%$ showed negative. This means that the majority of the participants in the study demonstrate that the implementation of 2030 in Saudi Arabia will expand the growth, use and demand over the need for developing teaching EFL in Saudi. Also, they pointed out that the implementation of 2030 Vision is a positive indicator towards achieving the target of teaching and learning English in Saudi Arabia.

Figure 1.1: The Impact of the Implementation of VAS 2030 on Teaching EFL at Higher Education Stage in Saudi Arabia from Saudi Female EFL Teachers' Perspectives from Female Teachers Perspectives.

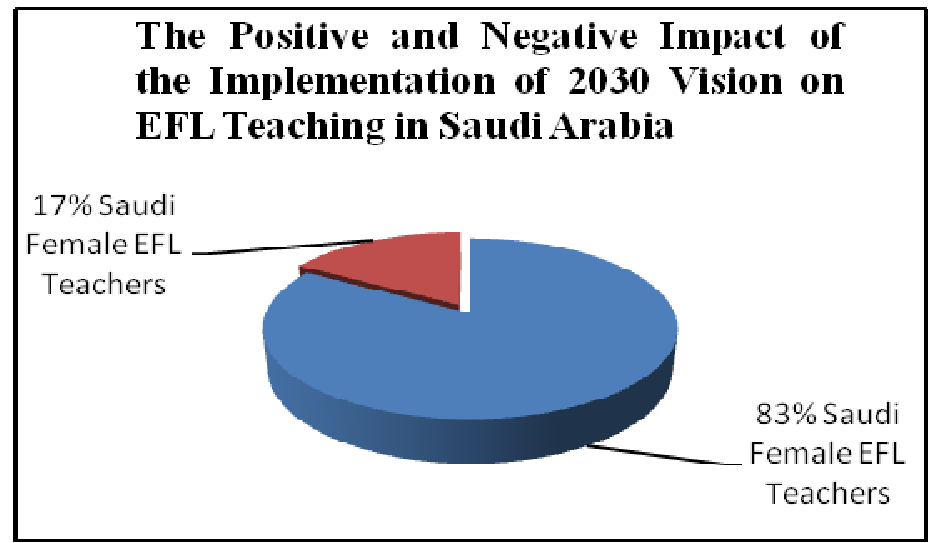

In response to research question two which investigates the perceptions of EFL teachers at higher education stage towards teaching English as a foreign language in relevance to the implementation of VAS 2030 as well as their readiness in raising fresh graduates' performance at higher education stage in Saudi public universities, Figure 1.2 depicts the perceptions of EFL teachers at higher education towards teaching EFL according to VAS 2030 . 
Figure 1.2: The Perceptions of EFL Teachers at Higher Education Stage towards Teaching English as a Foreign Language in Relevance to the Implementation of VAS 2030 as well as their Readiness in Raising Fresh Graduates’ Performance at Saudi Public Universities

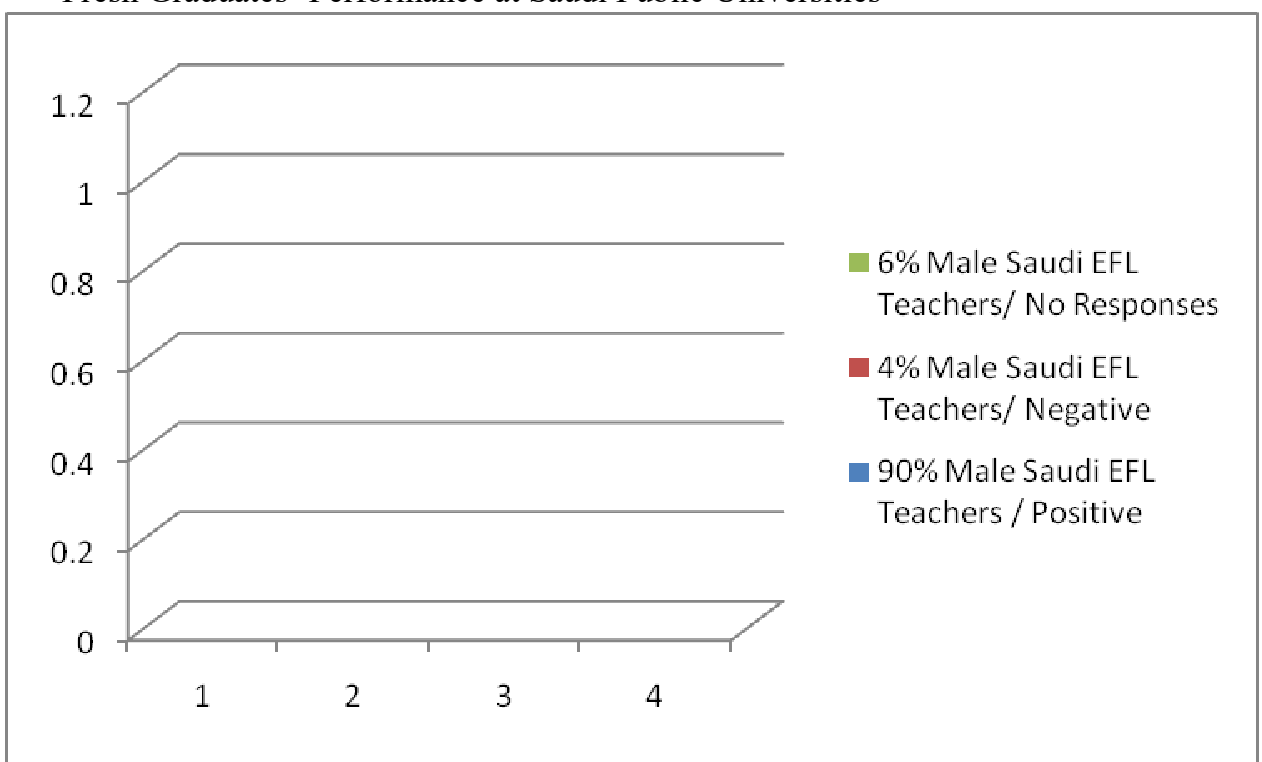

Figure 1.2 demonstrates that $6 \%$ of the male Saudi EFL teachers indicated no responses concerning their perceptions and readiness in raising the performance of fresh graduates in teaching and learning EFL at Saudi Public universities. Whilst, 4\% of the male Saudi EFL teachers showed negative responses about the impact of the implementation of VAS 2030 in accelerating or raising the performance of fresh EFL graduate students in learning and teaching EFL at Saudi public universities, in one hand. On the other hand, 90\% of the Saudi EFL male teachers were very positive and showed their readiness and high attitudes concerning the implementation of VAS 2030 effect on teaching / learning EFL at the Saudi public universities. To conclude, a very high percentage of Saudi Male and female teachers were very optimistic about the implementation of VAS 2030 and its role in the efficacy of teaching EFL which is shown in the readiness of female EFL teacher reporting $83 \%$ who strongly agreed that VAS 2030 will be very contributive to teaching EFL in Saudi Arabia. Also, 90\% of the participant Saudi male EFL teachers strongly agreed with the fact that the implementation of VAS 2030 will be very effective in teaching and learning English whether by developing teachers professionalism or their readiness showing positive attitudes concerning VAS 2030 implementation at higher education stage. In order to assess how the implementation of VAS 2030 affects the professional development of EFL teachers at higher education stage at the Saudi public universities, a Likert five-point scale in its foremost analytical descriptive items, each participant's response was used for this purpose as follows: strongly agree $=5$, agree $=4$, undecided $($ I do not know $)=5$, disagree $=2$, and Strongly disagree $=1$. Further, "strongly agree" and "agree" preferences were treated as positive items. Also, "disagree" and "strongly disagree" were treated as negative items. The items of the questionnaires investigated issues related to the impact of the implementation of vas 2030 on their daily life uses of EFL, improving vocabulary teaching, enhancing students' interaction, encouraging students learn EFL, develop their writing skills, improve students' listening skills, speaking skills, build personal skills and developing communication skills. The questionnaire survey was provided to a sample of EFL students at six Saudi public universities included The University of Tabuk, King Saud University, King Fahad University, Taiba University, King Abdulaziz University and King Khalid University. The collected results show the following:

i. $60 \%$ of the EFL teachers strongly agreed that the implementation of VAS 2030 affects the use of their daily life English use.

ii. $98 \%$ of the EFL teachers strongly agreed that the implementation of VAS 2030 can help EFL learners improve their English vocabulary.

iii. $96 \%$ of EFL teachers strongly agreed that the implementation of VAS 2030 will help Saudi EFL learners increase their interaction with learning English language.

iv. $75 \%$ of the EFL teachers strongly agreed that the implementation of VAS 2030 will sometimes encourage them to use technology for learning English language.

v. $96 \%$ of the EFL teachers strongly agreed that the implementation of VAS 2030 will help them to develop their writing skills.

vi. $33 \%$ of the EFL teachers strongly agreed that the implementation of VAS 2030 will be a good source of technology and inventing new teaching methods for learning English language. 
vii. $83 \%$ of EFL teachers strongly agreed that the implementation of VAS 2030 will improve their listening skills.

viii. $\quad 66 \%$ of EFL teachers strongly agreed and preferred that the implementation of new global trends and innovation such as VAS 2030 to learn English language since it will help create a genuine teaching environment.

ix. $98 \%$ of the EFL teachers strongly agreed that the implementation of VAS 2030 will help them to learn English language faster than other ways.

x. $90 \%$ of the EFL teachers strongly agreed that the implementation of VAS 2030 can help them to improve their speaking skills.

To conclude, in all the participating Saudi public universities EFL teachers, however, the implementation of VAS 2030 within most of the cases in the survey strongly agreed will impact the process of teaching and learning EFL. Also, they demonstrated that implementation of VAS 2030 will make them as EFL teachers and learners greatly dependent upon opportunistic access to new teaching techniques, methods and terminologies that were already heavily scheduled for specialist EFL curriculum designers, EFL teachers, decision makers or even vocational options. Consequently, although some planned and effective implementation of VAS 2030 will be an evident within the teaching and learning of core and foundation subjects, recent inspection reports indicated that such development will be uneven within all six Saudi Public Universities in particular and teaching as well learning EFL in varied Saudi universities, colleges and schools in both the public and private sectors in the Kingdom of Saudi Arabia. Finally, this study recommends that further future research be conducted in this field to examine the new trends of teaching and learning EFL in Saudi Arabia, particularly with the foundation of Neom City and Red Sea Project.

\section{References}

- Al-Essa, A. (2009). Education reform in Saudi Arabia between absence of political vision, apprehension the religious culture and disability of educational management. Beirut: Dar AlSakee.

- $\quad$ Al Mukhallafi, T. R. (2014). Computer assisted language learning for learning English in Saudi Arabia.

- Al-Nasser, A. S. (2015). Problems of English language acquisition in Saudi Arabia: An exploratory-cumremedial study. Theory and Practice in Language Studies, 5(8), 1612. https://doi.org/10.17507/tpls.0508.10.

- Al-Sulami, A. (2016, November 2). The First International Conference of English Languages Concludes Its Sessions in Jeddah.

- Al-Seghayer, K. (2014). The actuality, inefficiency, and needs of EFL teacher-preparation programs in Saudi Arabia. International Journal of Applied Linguistics \& English Literature 3(1), pp. 143-151.

- Al Zahrani. A. K. (2017). Marked and Language Policy in Saudi Arabia: How the English Language Can Contribute to the Success of the Saudi Vision 2030. International Journal of English Language and Linguistics Research Vol.5, No 6, pp. 1-12, UK.

- Alshumaimeri, Y. (2012). Education in Saudi Arabia. Retrieved from www.faculty.ksu.edu.sa.

- Faruk, S. G. (2013). English language teaching in Saudi Arabia: A world system perspective. Scientific Bulletin of the Politehnica University of Timiúoara Transactions on Modern Languages, 12 (1-2) 73-80.

- $\quad$ Melitz, J. (2008). Language and foreign trade. European Economic Review, 52(4), 667-699.

- Mahboob, A., \& Elyas, T. (2014). English in the kingdom of Saudi Arabia. World Englishes, 33(1), 128142 .

- $\quad$ Mosa, A. A. (2015). Pressures in Saudi Arabia. International Higher Education, (20).

- Ur Rahman, M. M., \& Alhaisoni, E. (2013). Teaching English in Saudi Arabia: Prospects and challenges. Academic Research International, 4(1), 112.

- Ministry of Education, Kingdom of Saudi Arabia (2013). English Language Curriculum for Elementary, Intermediate and Secondary Schools in the Kingdom of Saudi Arabia Grades 4 - 12, $2014-2020$ ISSN 2039-2117 (online) ISSN 2039-9340 (print) Mediterranean Journal of Social Sciences MCSER Publishing, Rome-Italy Vol 8 No 2 March 2017317 English Language Teaching in the Kingdom of Saudi Arabia: Past, Present and Beyond by Brendan Mitchell Abdulrahman Alfuraih.

- Mulhim, E. A. (2014). The barriers to the use of ICT in teaching in Saudi Arabia: A review of literature. Universal Journal of Educational Research 2(6): 487-493, DOI: 10.13189 Pinar, W. F., Reynolds, W. M., Slattery, P., \& Taubman, P. M.

- $\quad$ Yusuf, N., \& Atassi, H. (2016). Beyond Oil - The Transformation to a Market-Based Approach: Envision Saudi Arabia 2030. Journal of Economics and Sustainable Development, 7(14), 20-24.

- Yusuf. N. (2017). Changes Required in Saudi Universities Curriculum to Meet the Demands of 2030 Vision. International Journal of Economics and Finance; Vol. 9, No. 9; 2017 ISSN 1916-971X E-ISSN 1916-9728. Canadian Center of Science and Education, CA. 